\title{
Support effects in a Rh diamine complex heterogenized on carbon materials
}

\author{
C. C. Gheorghiu,${ }^{[a]}$ C. Salinas Martínez de Lecea ${ }^{[a]}$ and M.C. Román Martínez *[a]
}

The Rh diamine complex, [Rh(COD) $\left.\mathrm{NH}_{2}\left(\mathrm{CH}_{2}\right)_{2} \mathrm{NH}\left(\mathrm{CH}_{2}\right)_{3} \mathrm{Si}\left(\mathrm{OCH}_{3}\right)_{3}\right]$ $\mathrm{BF}_{4}$ has been heterogenized by covalent bonding on two carbon xerogels and on carbon nanofibers, with the objective of preparing hydrogenation hybrid catalysts. Gas adsorption, SEM, TEM, DTP, ICP-OES and XPS were used for characterization. The results indicate that the active molecule is mainly located in supermicropores and produces microporosity blockage. The hybrid catalysts are more

\section{Introduction}

The anchorage of metal complexes with catalytic activity on solid supports might lead to heterogeneous catalytic systems with the beneficial aspects of both, homogenous and heterogeneous catalysts: a high activity and selectivity, being easy to handle and to recover. The procedure is known as heterogenization of homogenous catalysts, and leads to the so-called hybrid catalysts.

The solid used as support plays a very important role in the properties of the hybrid system. The textural properties have a clear effect in the location of the active species on the support surface, and thus, they may have an influence in potential diffusion limitations and confinement and single site effects. ${ }^{[1-3]}$ On the other hand, the surface chemistry largely determines the interaction between the support and the metal complexes.

Carbon materials are very suitable catalyst supports due, mainly, to their high versatility in textural properties and surface chemistry, chemical stability in many reaction conditions, and the ease to recover the active phase. ${ }^{[4]}$ The use of nanostructured carbon materials has proven to be beneficial for preparing hybrid catalysts. ${ }^{[5]}$ The nanometric porosity dimension allows the anchorage of relatively voluminous active species that should also interact with relatively large substrates in liquid media.

Previous works have already revealed the importance of the carbon materials properties in their role as supports for hybrid catalysts. Some general publications that reveal the importance of carbon materials for this application can be found in the literature. ${ }^{[5-7]}$ Díaz-Auñon et al. ${ }^{[8]}$ found that the immobilization of the palladium complex $\left[\mathrm{PdCl}_{2}\left(\mathrm{NH}_{2}\left(\mathrm{CH}_{2}\right)_{2} \mathrm{CH}_{3}\right)_{2}\right]$ on a series of activated carbons with different textural properties and surface chemistry occurred by the physical adsorption of the ligand long aliphatic chain on the support surface, and not due to interaction with the surface oxygen groups. Because of the strong adsorption of metal complex on carbon surface, the catalyst remained stable. The catalytic activity in the hydrogenation of cyclohexene was found to be linearly dependent on the supermicropore volume of the support, concluding that the Pd complex was located in this type of pores. active than the homogeneous complex, but the Rh complex is partially reduced upon reaction. This modification has been related with the nature of the support, which has also shown to have an effect in the stabilization against sintering of the Rh particles formed. The support porosity is behind differences in selectivity between the catalysts.

Lemus-Yegres et al. ${ }^{[9]}$ developed hybrid catalysts by the covalent anchorage of the $\mathrm{Rh}$ complex $\left[\mathrm{Rh}(\mathrm{COD}) \mathrm{NH}_{2} \mathrm{CH}_{2} \mathrm{CH}_{2} \mathrm{NH}\left(\mathrm{CH}_{2}\right)_{3} \mathrm{Si}\left(\mathrm{OCH}_{3}\right)_{3}\right] \mathrm{BF}_{4}$ (where $\mathrm{COD}$ stands for cyclooctadiene), abbreviated as $\mathrm{Rh}(\mathrm{NN}) \mathrm{Si}$, on activated carbon, activated carbon fibers, activated carbon cloth, carbon nanotubes and carbon nanofibers. These catalysts were tested in the hydrogenation of cyclohexene and carvone. A linear relationship was found between the catalytic activity and the support external surface area. However, the catalysts prepared with carbon nanotubes and carbon nanofibres showed an outstanding behaviour, which was attributed to a confinement effect due to the location of the metal complex in the few nanometers sized hollow cavity of these supports. ${ }^{[9-12]}$ The work was extended using four multiwall carbon nanotubes of average inner diameter ranging from 4 to $10 \mathrm{~nm}$ as support. A clear effect of the inner cavity size of carbon nanotubes was observed. In the case of the thinner nanotubes (inner $\varnothing=4 \mathrm{~nm}$ ), the support does not produce a positive effect, and the catalysts prepared with nanotubes of inner diameter around $7 \mathrm{~nm}$ gave the best results. $^{[12]}$

Lemus-Yegres et al. also analyzed the effect of the supports surface chemistry ${ }^{[11]}$ using activated carbons prepared by oxidation with $\mathrm{HNO}_{3}$ and $\left(\mathrm{NH}_{4}\right)_{2} \mathrm{~S}_{2} \mathrm{O}_{3}$ aqueous solutions and synthetic air. The catalyst prepared with the air treated activated carbon was more active, stable and reusable, with practically no leaching of the metal complex. The presence of a large amount of oxygen groups (produced with the aqueous solution treatments) hinders the location of the complex inside the porosity having a negative effect on the catalytic activity.

Almost in all cases, reutilization of the hybrid catalysts

[a] C.C. Gheorghiu, Prof. C. Salinas Martínez de Lecea and Prof. M. C. Román Martínez

Department of Inorganic Chemistry

University of Alicante

ctra San Vicente del Raspeig $s / n$. Alicante. Spain

Fax: (+34 965903454)

E-mail:mcroman@ua.es

Supporting information for this article is available on the WWW under http://dx.doi.org/10.1002/cctc.200xxxxxx.((Please delete if not appropriate)) 
showed an increase of the catalytic activity in the second and following runs that was attributed to complex modifications during the first catalytic run. It was suggested that the COD ligand is hydrogenated in the first catalytic run and substituted by solvent molecules. ${ }^{[11]}$

The broad variety of available carbon materials opens the possibility of seeking for a carbon support that would improve the properties of the hybrid catalysts. The present work is focused on the use of two different carbon materials to anchor the $\mathrm{Rh}$ diamine complex Rh(NN)Si. These are two carbon xerogels of different porosity, with a large proportion of mesopores, and carbon nanofibres, essentially microporous and with a considerable external surface area. The immobilization is based on the creation of a siloxane type covalent bond between the trimethoxysilane $\left(-\mathrm{Si}\left(\mathrm{OCH}_{3}\right)_{3}\right)$ ligand functionality and phenol type groups developed on the supports surface upon oxidation. ${ }^{[10]}$

The work carried out involves both, the thorough characterization of the carbon supports and hybrid catalysts, and the analysis of the catalytic behaviour and the modification of the catalysts upon hydrogenation reactions. The objective is to determine the effect of porosity and the nature of carbon materials on the catalysts properties.

\section{Results and Discussion}

\section{Supports characterization}

\section{Porous texture}

Figure 1 shows the $\mathrm{N}_{2}$ adsorption isotherms at $77 \mathrm{~K}$ obtained for samples CX1Ox, CX2Ox and NFLOx. Both carbon xerogels show type I+IV adsorption isotherms, (IUPAC classification ${ }^{[13]}$ ), indicating the presence of micropores and mesopores. Differences in the isotherms slope, total adsorption, and hysteresis loops reveal differences in the porosity (pore size distribution and volume) of the two carbon xerogels. The $\mathrm{N}_{2}$ adsorption isotherm obtained for the carbon nanofibres (NFLOx) is mainly type I, showing the microporous character of this material. However, the presence of a small tail at high relative pressures denotes the existence of pores or interparticle space in the mesopore range.

The mesopore size distribution has been determined from the desorption branch of the $\mathrm{N}_{2}$ adsorption isotherm by applying the BJH method. ${ }^{[14]}$ The obtained profiles are shown in Figure 2, in which a bimodal distribution is observed for the three samples. The second maximum reveals considerable differences between the samples as it is located at approximately 10, 20 and $50 \mathrm{~nm}$ for CX2Ox, CX1Ox and NFLOx, respectively.

Table 1 includes the surface area and porosity parameters corresponding to the original and oxidized samples.

The textural properties of carbon xerogels CX1 and CX2 are almost unchanged after the oxidation treatment, however a significant increase of the BET surface area and the total and narrow micropore volumes of sample NFLOx is produced while mesopore volume slightly decreases. The original NFL sample has very narrow micropores as demonstrated by the smaller value of the $V \mu t$ with respect to $V u \mu .^{[15,16]}$

Comparing the oxidized samples, CX1Ox has the largest mesopore volume and the wider mesopores (Figure 2), but the micropore volume is similar to that of CX2Ox. Sample NFLOx has the smallest micropore and mesopore volume.

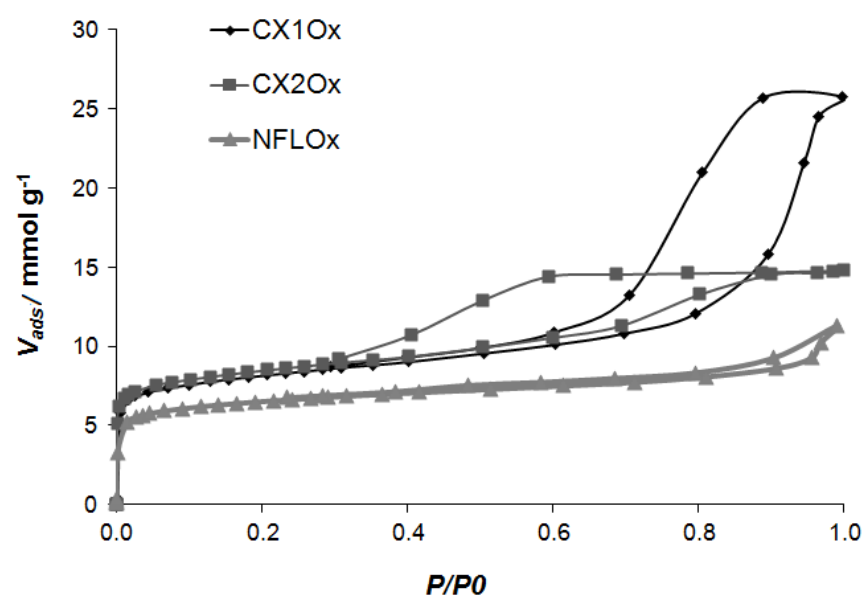

Figure 1. $\mathrm{N}_{2}$ adsorption isotherms at $77 \mathrm{~K}$.

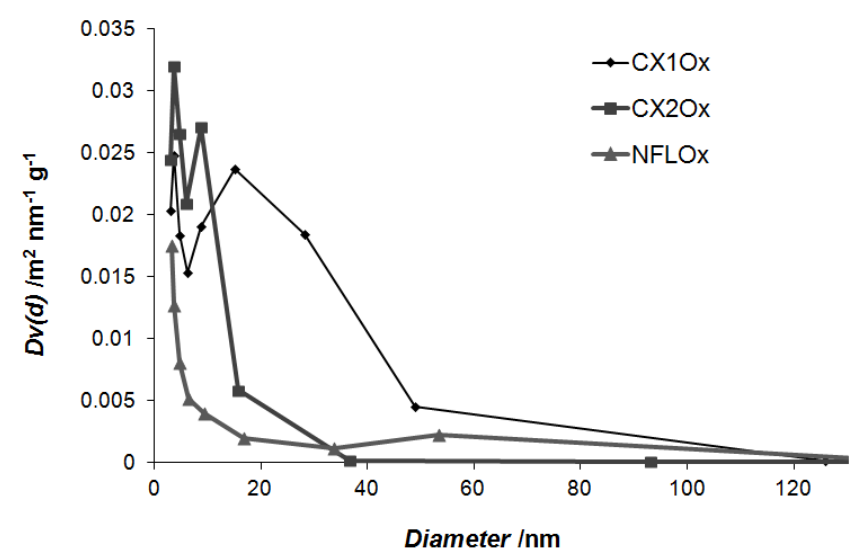

Figure 2. Pore size distribution determined from desorption branch of the $\mathrm{N}_{2}$ adsorption isotherm by the BJH method. ${ }^{[14]}$

\begin{tabular}{|c|c|c|c|c|c|}
\hline Sample & $\begin{array}{l}S_{\text {BET }} \\
{\left[m^{2} g^{-1}\right]}\end{array}$ & $\begin{array}{l}V_{\mu t} \\
{\left[\mathrm{~cm}^{3} \mathrm{~g}^{-1}\right]}\end{array}$ & $\begin{array}{l}V_{u \mu} \\
{\left[\mathrm{cm}^{3} \mathrm{~g}^{-1}\right]}\end{array}$ & $\begin{array}{l}V_{s \mu} \\
{\left[\mathrm{cm}^{3} \mathrm{~g}^{-1}\right]}\end{array}$ & $\begin{array}{l}V_{\text {meso }} \\
{\left[\mathrm{cm}^{3} \mathrm{~g}^{-1}\right]}\end{array}$ \\
\hline CX1 & 624 & 0.29 & 0.24 & 0.06 & 0.67 \\
\hline CX1Ox & 587 & 0.28 & 0.23 & 0.05 & 0.61 \\
\hline CX2 & 623 & 0.28 & 0.23 & 0.05 & 0.24 \\
\hline CX2Ox & 624 & 0.29 & 0.25 & 0.04 & 0.22 \\
\hline NFL & 156 & 0.07 & 0.14 & - & 0.21 \\
\hline NFLOx & 463 & 0.23 & 0.20 & 0.03 & 0.15 \\
\hline \multicolumn{6}{|c|}{$\begin{array}{l}\mathrm{S}_{\mathrm{BET}}-\mathrm{BET} \text { surface area, } \mathrm{V}_{\mu^{-}} \text {total micropore volume, } \mathrm{V}_{\mathrm{u} \mu^{-}} \text {narrov } \\
\text { micropore volume, } \mathrm{V}_{\mathrm{s}^{-}} \text {supermicropore volume, } \mathrm{V}_{\text {meso- }} \text { mesopore } \\
\text { volume, Parameters described in the literature. }\end{array}$} \\
\hline
\end{tabular}

As revealed by the different hysteresis loops observed in the $\mathrm{N}_{2}$ adsorption isotherms (Figure 1), the samples have also a different porous structure that will be commented in the morphology section. 


\section{Surface chemistry}

Figure 3 shows the $\mathrm{CO}$ and $\mathrm{CO}_{2}$ evolution profiles obtained in TPD experiments for samples CX1 and CX1Ox (Figure 3a), CX2 and CX2Ox (Figure 3b) and NFL and NFLOx (Figure 3c). The oxidation treatment with air mainly produces surface oxygen groups decomposing as $\mathrm{CO}$ at relatively high temperature (around $900 \mathrm{~K}$ ) in part corresponding to phenol type groups. Both carbon xerogel samples have a very similar surface chemistry while sample NFLOx contains surface groups that decompose above $1200 \mathrm{~K}$.

a)

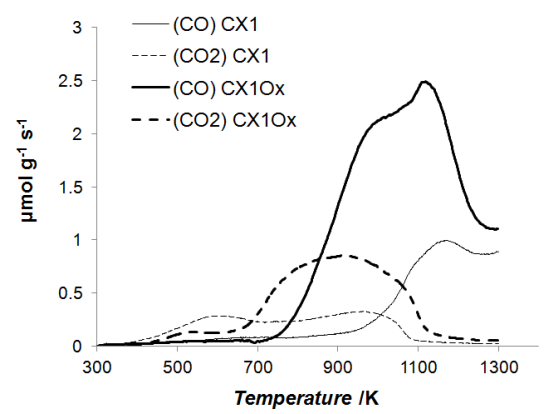

b)

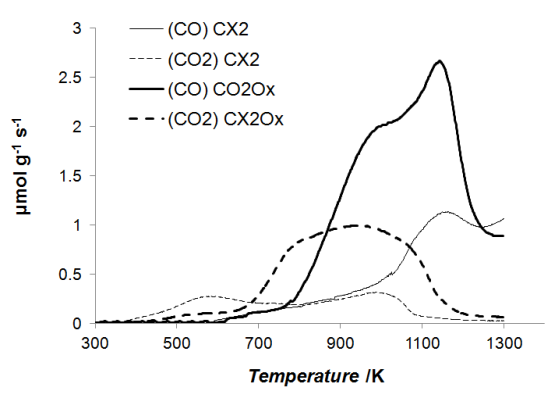

c)

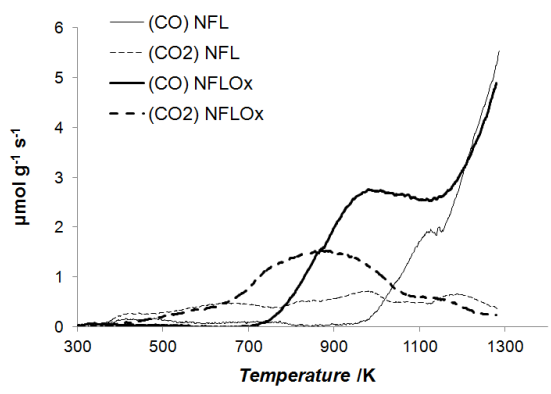

Figure 3. $\mathrm{CO}$ and $\mathrm{CO}_{2}$ TPD profiles of the original and oxidized samples (a) CX1 and CX1Ox; (b) CX2 and CX2Ox; (c) NFL and NFLOx (be aware of the different scale).

Table 2 shows the quantification of the TPD profiles as the amount of $\mathrm{CO}$ and $\mathrm{CO}_{2}$ evolved (in $\mu \mathrm{mol} \mathrm{g}^{-1}$ ) and oxygen weight percentage. The amount of phenol type groups has been determined by deconvolution of the $\mathrm{CO}$ evolution profile considering that they decompose between $873 \mathrm{~K}$ and $973 \mathrm{~K}^{[17,18]}$ and it is included in Table 2.

Assuming that the anchorage takes place by the creation of three siloxane type bonds, three surface phenol type groups per complex molecule are necessary.
Thus, if the phenol groups on the supports surface are accessible and close enough to form the three mentioned bonds, the anchorage of an amount of Rh complex corresponding to $2 \mathrm{wt} \%$ $\mathrm{Rh}(192 \mu \mathrm{mol})$ might be achieved sufficiently.

\begin{tabular}{|c|c|c|c|c|}
\hline Sample & $\begin{array}{l}\mathrm{CO} \\
{\left[\mu \mathrm{mol} \mathrm{g}{ }^{-1}\right]}\end{array}$ & $\begin{array}{l}\mathrm{CO}_{2} \\
{\left[\mu \mathrm{mol} \mathrm{g}{ }^{-1}\right]}\end{array}$ & $\begin{array}{l}\mathrm{O} \\
{[\%]}\end{array}$ & $\begin{array}{l}\text { Phenol } \\
\left.[\mu \mathrm{mol} \mathrm{g}]^{-1}\right]^{[a]}\end{array}$ \\
\hline CX1 & 860 & 505 & 3.0 & 38 \\
\hline CX10x & 2578 & 989 & 7.3 & 1335 \\
\hline CX2 & 1067 & 474 & 3.2 & 210 \\
\hline CX2Ox & 2501 & 1184 & 7.8 & 1287 \\
\hline NFL & 2291 & 1296 & 7.8 & 16 \\
\hline NFLOx & 3956 & 1979 & 12.7 & 2110 \\
\hline
\end{tabular}

\section{Morphology}

The oxidized supports have been observed by SEM and TEM. No significant differences between the two carbon xerogel samples have been found. As an example, Figures $4 \mathrm{a}$ and $4 \mathrm{~b}$ show, respectively, SEM and TEM micrographs of sample CX1Ox. SEM images show a smooth and straight surface that appears rippled and lined at a higher magnification (inset in Figure 4a). TEM images show the spongy agglomerate aspect with tortuous pore network. a)

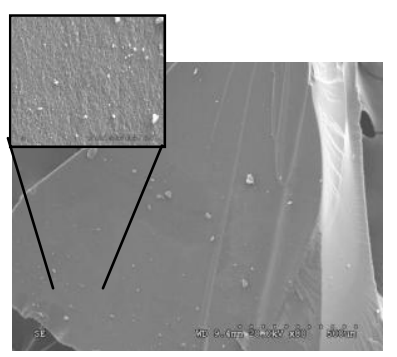

b)

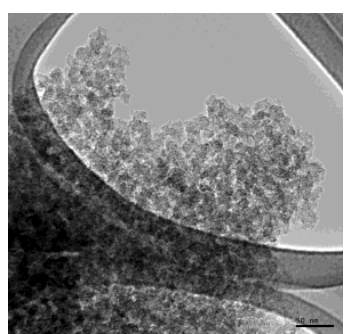

Figure 4. (a) SEM images and (b) TEM image of the oxidized carbon xerogel CX1Ox.

Figures $5 a$ and $5 b$ show SEM and TEM images of sample NFLOx. Groupings of several nanofibers in parallel are observed. TEM images show that the nanofibres are massive (without internal hole), with a mean individual diameter between 50-100 nm. The morphology and the fibres mean diameter have not been modified by the oxidation treatment.

From the textural and morphological characterization it can be outlined that carbon xerogels have an interconnected pore network ranging from the meso to the micropore sizes. The main difference among the two carbon xerogels is the size of the largest mesopores (Figure 2). The porosity of the carbon nanofibers is composed of microporosity inside the massive cylindrical structure, and voids in the mesopore size range, due to the nanofibres entanglement and the formation of bundles. 
a)

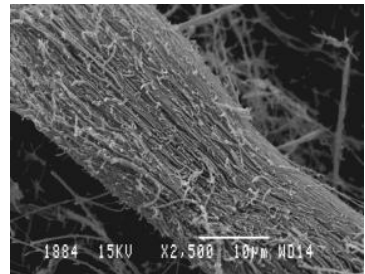

b)

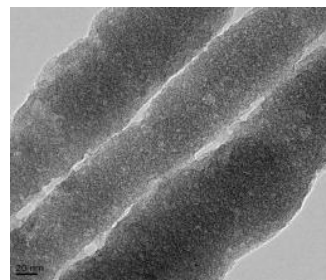

Figure 5. (a) SEM image and (b) TEM image of the oxidized nanofibres NFLOx.

\section{Characterization of the Rh(NN)Si complex synthesized}

The synthesized complex was analyzed by FT-IR, XPS and elemental analysis. The FTIR spectrum shows absorption peaks at: $3300 \mathrm{~cm}^{-1}$ (assigned to N-H stretch), $2950 \mathrm{~cm}^{-1}$ (corresponding to the asymmetrical vibration $\mathrm{C}-\mathrm{H}$ of the aliphatic chain of the (NN)Si ligand and of the 1,5-cyclooctadiene), $1600 \mathrm{~cm}^{-1}$ (corresponding to the $\mathrm{Si}-\mathrm{C}$ vibration), $1080 \mathrm{~cm}^{-1}$ (assigned to $\mathrm{Si}-\mathrm{O}$ vibration). XPS data show $\mathrm{Rh}^{\prime}$ and nitrogen as amine. However, the $\mathrm{N} / \mathrm{Rh}$ ratio is 3 , higher than the expected value of 2 . On the other hand, elemental analysis indicates that the $\mathrm{N}, \mathrm{C}$ and $\mathrm{H}$ proportions are not exactly those expected. Thus, these data suggest that the synthesized sample contains the two metal complexes presented in Scheme 1: the diamine complex and a bis-diamine complex named here $\left[\mathrm{Rh}\left\{(\mathrm{NN}) \mathrm{Si}_{2}\right]\right.$. The proportion of each species in the mixture has been estimated to be about $50 \%$.

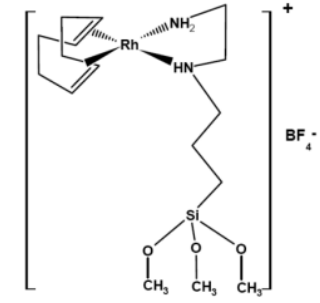

[Rh(NN)Si]

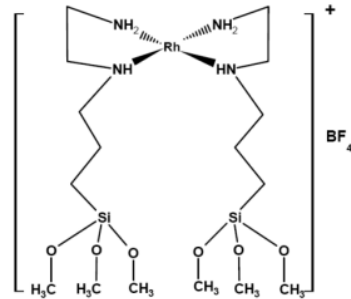

$\left[\mathrm{Rh}\left\{(\mathrm{NN}) \mathrm{Si}_{2}\right]\right.$
Scheme 1. Chemical structure of $[\mathrm{Rh}(\mathrm{NN}) \mathrm{Si}]$ and $\left[\mathrm{Rh}\{(\mathrm{NN}) \mathrm{Si}\}_{2}\right]$ complexes.

\section{Characterization of the hybrid catalysts}

\section{Complex loading}

The amount of Rh determined by ICP-OES in the two carbon xerogels is $0.5 \mathrm{wt} \%$, corresponding to $46 \mu \mathrm{mol}$ of complex per gram of sample, while it is 0.9 wt $\%$ for sample NFLOx, corresponding to $87 \mu \mathrm{mol}$ of complex per gram of sample. These values are lower than the amount of Rh used in the catalysts preparation (192 $\mu \mathrm{mol}$ of complex per gram of support, corresponding to $2 \mathrm{wt} \% \mathrm{Rh})$. Elemental analysis of catalysts CX1Ox-Rh and CX2Ox-Rh gives a nitrogen amount of about 400 $\mu \mathrm{mol} \mathrm{g}{ }^{-1}$. The carbon xerogels themselves do not contain nitrogen and thus, this result means that about $200 \mu \mathrm{mol} \mathrm{g}^{-1}$ of ligand have been anchored, which involves the reaction with $600 \mu \mathrm{mol} \mathrm{g}^{-1}$ of phenol type oxygen surface groups (if three siloxane bonds have been formed per mol of ligand anchored). This indicates that not all of the available surface phenol type groups have been used for the anchorage, likely because they are not accessible or close enough to form the required arrangements.

According to these data, $200 \mu \mathrm{mol} \mathrm{g}{ }^{-1}$ of ligand have been anchored, this amount is higher than that corresponding to the loaded $\mathrm{Rh}$, meaning that some decomplexation takes place during the anchorage process.

\section{Complex size}

An estimation of the molecular size of the metal complex was carried out in order to work out its location in the support porosity. Scheme $2 \mathrm{a}$ is a perspective view of the $\left[\mathrm{Rh}(\mathrm{COD}) \mathrm{NH}_{2}\left(\mathrm{CH}_{2}\right)_{2} \mathrm{NH}\left(\mathrm{CH}_{2}\right)_{3} \mathrm{Si}\left(\mathrm{OCH}_{3}\right)_{3}\right] \mathrm{BF}_{4}$ complex showing the main interatomic distances. Scheme $2 b$ shows the structure of the complex bis-diamine. The estimated dimensions of these Rh complexes are around $12.5 \AA$ long and $11.5 \AA$ broad, indicating that they are capable of fitting in supermicropores. a)

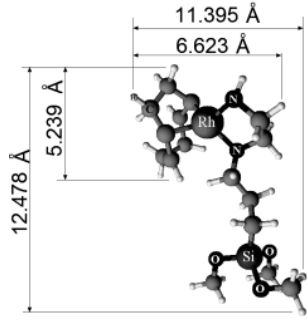

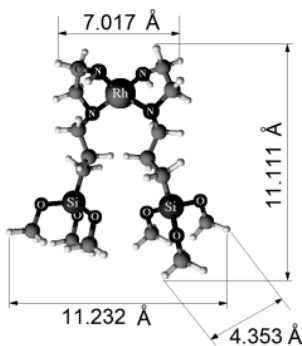

Scheme 2. Molecular structure of complexes: (a) [Rh(NN)Si] and (b) $\left[\mathrm{Rh}\{(\mathrm{NN}) \mathrm{Si}\}_{2}\right]$.

XPS and TEM analysis.

XPS data obtained for the hybrid catalysts and the unsupported complex are shown in Table 3.

\begin{tabular}{|c|c|c|c|c|}
\hline \multirow{2}{*}{ Sample } & \multicolumn{4}{|c|}{ Binding energy [eV] } \\
\hline & $\operatorname{Rh} 3 d_{5 / 2}$ & $\mathrm{~N} 1 \mathrm{~s}$ & $\mathrm{~N} / \mathrm{Rh}$ & $F=R h_{X P S} / R h_{I C P}$ \\
\hline $\mathrm{Rh}(\mathrm{NN}) \mathrm{Si}$ & 309.1 & 400.3 & 3 & - \\
\hline CX10x-Rh & 309.4 & 400.6 & 6 & 16 \\
\hline CX2Ox-Rh & 308.9 & 400.5 & 6 & 35 \\
\hline NFLOx-Rh & 309.7 & 399.8 & 4 & 5 \\
\hline
\end{tabular}

The binding energy of $R h 3 d_{5 / 2}$ in the hybrid catalysts corresponds to $\mathrm{Rh}^{1}{ }^{[19]}$, indicating that the electronic state of $\mathrm{Rh}$ in the complex is almost not modified upon heterogenization. The binding energy found for $\mathrm{N} 1 \mathrm{~s}$ is characteristic of $\mathrm{N}$ in amine and is similar to that measured for the homogeneous complex.

The high N/Rh ratio found (the expected one should be between 2 and 4, considering the two molecules shown in Scheme 1), particularly in the case in the two carbon xerogel based catalysts, supports the partial decomplexation occurring during the grafting process, as indicated above.

The factor $F$, calculated as the ratio between the amount of $R h$ determined from XPS and ICP ( $\left.F=R h_{X P S} / R h_{I C P}\right)$, can give an idea about the location of the complex in the carbon porosity. ${ }^{[9]} \mathrm{A}$ lower $F$ value corresponds to a more internal location, because a larger proportion of the Rh complex is not detected by the XPS technique. 
The values of $F$ indicate that the $R h$ atoms are more internally located in the case of catalyst NFLOx-Rh, followed by catalyst CX1Ox-Rh and CX2Ox-Rh with the highest value, corresponding to the more externally located $\mathrm{Rh}$ complex. In a previous study, using an activated carbon as support, the catalyst ROXOx-Rh presented a $\mathrm{F}$ value of $10^{[11]}$ indicating that in the carbon xerogels the complex distribution is more external, probably as a consequence of the different porosity.

The TEM analysis of the fresh hybrid catalysts does not reveal the presence of visible metallic particles, and thus, in agreement with the XPS data, fresh catalysts do not contain $\mathrm{Rh}^{0}$.

\section{Textural properties}

The textural properties of the hybrid catalysts CX1Ox-Rh, CX2Ox-Rh and NFLOx-Rh have been also analyzed by $\mathrm{N}_{2}$ and $\mathrm{CO}_{2}$ adsorption. A comparison of the adsorption isotherms of catalysts and supports is presented as supporting information (Figures S1 and S2).

The obtained data indicate that the anchored complex produces a decrease in the adsorption capacity. The textural properties of the hybrid catalysts (BET surface area, pore volumes and pore size distributions) have been calculated as in the case of supports. The surface areas of the catalysts are lower than those of the corresponding supports, being the reduction of $40 \%, 27 \%$ and $84 \%$ for samples CX1Ox-Rh, CX2Ox-Rh, and NFLOx-Rh, respectively. Figure 6 shows the pore volumes of the supports and hybrid catalysts.

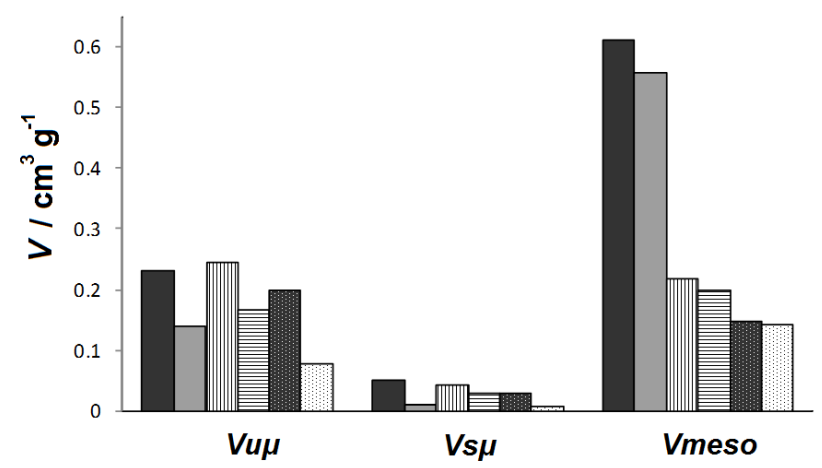

-CX10x 口CX1Ox-Rh 四CX2Ox 目CX2Ox-Rh 國NFLOx 四 NFLOx-Rh

Figure 6. Pore volumes of the supports and catalysts.

Data of Figure 6 show that the porosity blockage by the anchored complex affects particularly to the micropores ( $\mathrm{Vu \mu}$ and $\mathrm{V} s \mu$ ). This effect is more pronounced in the case of the catalyst prepared with the carbon nanofibers.

The mesopore size distribution of catalysts CX1Ox-Rh, CX2Ox$\mathrm{Rh}$ and NFLOx-Rh has been also determined by the BJH method. $^{[14]}$ No significant modification after complex immobilization was found.

A correlation between the micropores blockage and the $F$ value (Table 3) has been found. The most pronounced porosity variation is found for catalyst NFLOx-Rh with the smallest $F$ value $(F=5)$. It is followed by catalyst $\mathrm{CX} 10 x-\mathrm{Rh}(\mathrm{F}=16)$, and then, by catalyst $\mathrm{CX} 2 \mathrm{Ox}-\mathrm{Rh}$ with $\mathrm{F}=35$ and the slightest porosity variation. That is, a more internal location (lower value of $F$ ) of the $R h$ complex is related with a higher porosity blockage.

Thus, the anchored Rh complex produces a partial blockage of the microporosity, which can be interpreted considering that it is located either at the entrance of some microcropores, blocking their entrance; or partially or totally inside pores with a diameter smaller than $2 \mathrm{~nm}$ (in agreement with the complex dimensions, Scheme 2). Such an interpretation of the metal complex location has been previously provided. ${ }^{[8]}$ Considering the differences in mesopore size distribution, it seems that the larger the mesopores more internally is the complex located. In fact, for the support with the smallest mesopore size (CX2Ox-Rh) also a slight decrease in mesopore volume is observed. For the two carbon xerogels, it may be concluded that the differences in mesopore size affect the location of the Rh complex, being more externally located in catalyst CX2Ox-Rh. This could have an effect in the diffusion of reactants and products through the catalyst porosity, to and from the active centres affecting the selectivity of the catalyst.

\section{Catalytic activity and recycling}

Cyclohexene hydrogenation

Blank experiments were carried out: i) without catalyst (only substrate and solvent); and ii) with the supports. These activity tests gave negligible substrate conversion.

Figure 7 shows cyclohexene conversion versus time profiles, obtained from $\mathrm{H}_{2}$ consumption data, for the three hybrid catalysts and the homogeneous complex $\mathrm{Rh}(\mathrm{NN}) \mathrm{Si}$.

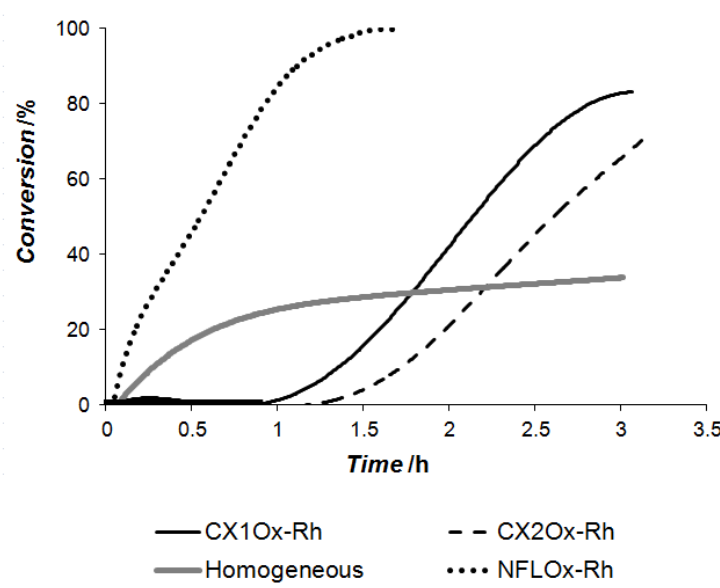

Figure 7. Cyclohexene conversion versus time with the homogeneous $\mathrm{Rh}(\mathrm{NN}) \mathrm{Si}$ complex and the three hybrid catalysts. 5 vol. \% cyclohexene in methanol, 10 bar $\mathrm{H}_{2}, 333 \mathrm{~K}$.

The $\mathrm{H}_{2}$ consumption is consistent with the product analysis at the end of the experiments. The hybrid catalysts have a catalytic activity higher than that of the homogeneous complex, being catalyst NFLOx-Rh the most active. In the case of catalysts $\mathrm{CX} 1 \mathrm{Ox}-\mathrm{Rh}$ and $\mathrm{CX} 2 \mathrm{Ox}-\mathrm{Rh}$ there is an induction time previous to the reaction. Table 4 shows cyclohexene conversion and TOF values, at 180 minutes for the homogeneous and carbon xerogels based catalysts, and at 60 minutes for catalyst NFLOx-Rh.

In order to make a proper comparison of the three hybrid catalysts, skipping the induction period, activity has been calculated by determining the maximum slope of the curves shown in Figure 7. These results are also presented in Table 4.

The higher activity of the hybrid catalysts compared to the homogeneous complex indicates that the support exerts a positive effect in the catalyst behaviour. A confinement effect of the active species in the porosity of the support could be behind the enhanced activity. It has been reported ${ }^{[9,20]}$ that when the 
complex is immobilized in the support porosity, the reactants are confined close to the active molecule, and this enhances the catalytic activity.

\begin{tabular}{|c|c|c|c|}
\hline Sample & $\begin{array}{l}\text { Conversion } \\
{[\%]}\end{array}$ & $\begin{array}{l}\text { TOF } \\
{\left[\mathrm{s}^{-1}\right]}\end{array}$ & $\begin{array}{l}\text { Slope }_{\text {max }} \\
{\left[\mathrm{ml} \mathrm{h}^{-1}\right]}\end{array}$ \\
\hline $\begin{array}{l}\text { Homogeneous } \\
\mathrm{Rh}(\mathrm{NN}) \mathrm{Si}^{[\mathrm{a}]}\end{array}$ & 33 & 0.08 & 40 \\
\hline CX10X-Rh ${ }^{[a]}$ & 80 & 0.29 & 75 \\
\hline CX2OX-Rh ${ }^{[\mathrm{a}]}$ & 70 & 0.24 & 55 \\
\hline NFLOx-Rh ${ }^{[b]}$ & 92 & 0.45 & 100 \\
\hline
\end{tabular}

[a] Conversion and TOF calculated at 180 minutes.

[b] Conversion and TOF calculated at 60 minutes.

The behaviour of the two carbon xerogel based hybrid catalysts is similar, being catalyst CX1Ox-Rh slightly more active, while catalyst NFLOx-Rh is clearly the most active. Taking into account the value of $F=R h_{X P S} / R h_{\text {ICP }}$ (see Table 3), an inverse relationship between this parameter and the activity is observed, and this allows to propose that a more internal location leads to a higher activity. This could be explained considering that in an internal location the confinement effect is more pronounced.

A comparison of these catalysts to some other similar, previously studied, indicates that catalyst $\mathrm{CX} 1 \mathrm{Ox}-\mathrm{Rh}$ shows an activity similar to that of the one prepared with a commercial activated carbon, sample ROXOx-Rh, although considerably lower than that obtained with a carbon nanotubes based catalyst, NT7$R .^{[9,10,12]}$ The higher activity of this catalyst was justified by the location of the metal complex in the mesopores of tubular shape, in contrast with the micropore location in the case of the xerogels and activated carbon based catalysts. Then, it can be concluded that the high activity of the carbon nanotubes and hollow carbon nanofibres supported catalyst is not achieved with the carbon xerogel based catalysts due to the existence of microporosity in addition to mesoporosity (carbon nanotubes exhibit only mesopores). This highlights the importance of the metal complex location in a nanosized cavity.

\section{Recycling tests}

The catalysts reusability has been studied following the procedure described in the experimental section. Figure 8 shows the conversion versus time curves obtained in four consecutive catalytic runs with catalyst $\mathrm{CX} 10 \mathrm{x}-\mathrm{Rh}$. In the second and consecutive runs there is not induction time and the catalytic activity is noticeably enhanced. The experiments were stopped at conversions near to $90 \%$. A similar behaviour is observed for catalyst CX2Ox-Rh.

Figure 9 presents the cyclohexene conversion versus time curves obtained in four consecutive catalytic runs with NFLOx-Rh catalyst. In this case, a completely different trend is observed as the activity decreases in consecutive catalytic runs.

Table 5 collects activity data expressed as TOF $\left(\mathrm{s}^{-1}\right)$, calculated at $50 \%$ conversion (including the corresponding time), of the three hybrid catalysts in consecutive runs.

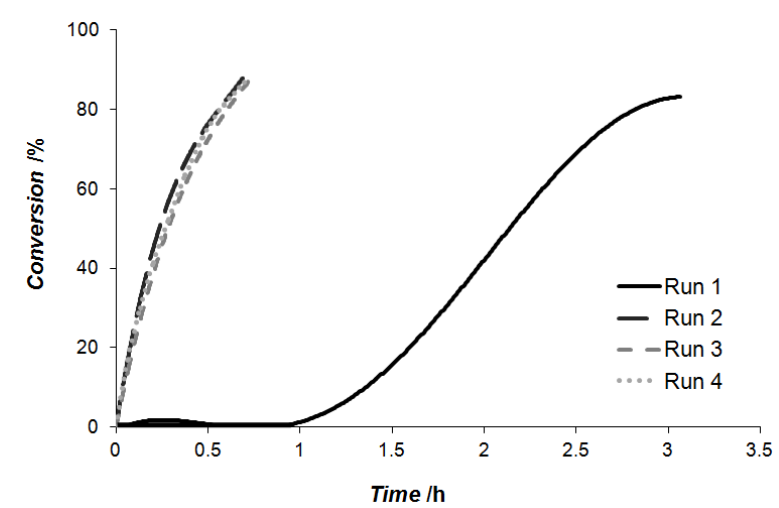

Figure 8. Cyclohexene conversion in four consecutive catalytic runs for catalyst CX1Ox-Rh. 5 vol. \% cyclohexene in methanol, 10 bar $\mathrm{H}_{2}$, 333K.

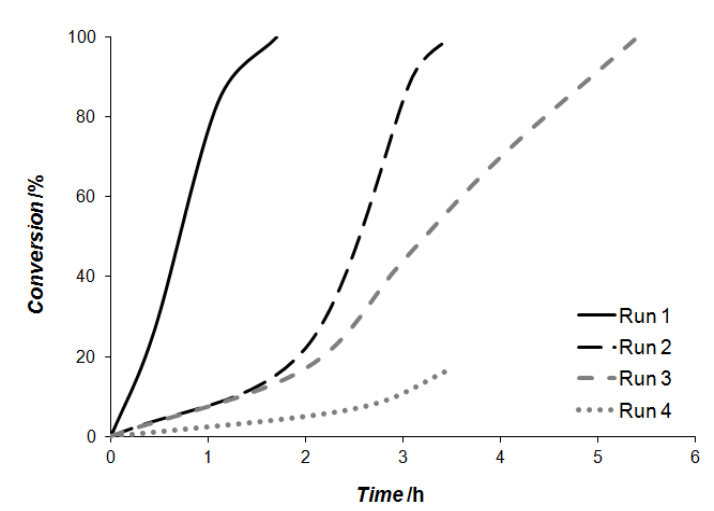

Figure 9. Cyclohexene conversion in four consecutive catalytic runs for catalyst NFLOx-Rh. 5 vol. cyclohexene in methanol, 10 bar $\mathrm{H}_{2}, 333 \mathrm{~K}$.

\begin{tabular}{|c|c|c|c|c|}
\hline Sample & Run & $\begin{array}{l}\text { TOF } \\
{\left[s^{-1}\right]^{[a]}}\end{array}$ & $\begin{array}{l}\text { Time } \\
{[\mathrm{min}]^{[\mathrm{a}]}}\end{array}$ & $\begin{array}{l}\text { Slope }_{\max } \\
{\left[\mathrm{ml} \mathrm{h}^{-1}\right]}\end{array}$ \\
\hline \multirow{3}{*}{ CX10x-Rh } & 1 & 0.26 & 126 & 75 \\
\hline & 2 & 1.86 & 18 & 152 \\
\hline & 3 & 1.87 & 18 & 158 \\
\hline \multirow{3}{*}{ CX2Ox-Rh } & 1 & 0.22 & 150 & 55 \\
\hline & 2 & 0.96 & 32 & 95 \\
\hline & 3 & 1.63 & 21 & 137 \\
\hline \multirow{3}{*}{ NFLOx-Rh } & 1 & 0.48 & 35 & 100 \\
\hline & 2 & 0.20 & 150 & 92 \\
\hline & 3 & 0.09 & 180 & 31 \\
\hline
\end{tabular}

These data show that the support properties play an important effect in the catalytic behaviour of the hybrid catalysts. For the carbon xerogel supported catalysts, a significant increase of TOF in successive runs was observed. However, it must be taken into consideration that in the first run the induction period is present, and for a more accurate quantification, the reaction rate has been 
expressed as the maximum slope of the curves. Variations of the catalytic activity after the first run must be attributed to modifications of the complex under reaction conditions leading to different species. The enhancement of the catalytic activity has been previously observed and it was attributed to a change in the metal coordination sphere by hydrogenation of the cyclooctadiene ligand. ${ }^{[11]}$ The activity loss has been attributed to catalyst modifications or lixiviation. ${ }^{[11]}$ Therefore, the characterization of the used catalysts is of paramount importance to provide an explanation.

\section{Study of the used catalysts}

The Rh content in fresh and used catalysts was similar and thus no significant leaching has been found.

The used samples, after 3 catalytic runs, were analyzed by TEM. TEM images of catalysts CX1Ox-Rh, CX2Ox-Rh and NFLOx-Rh are presented in Figure 10. The used catalysts show the presence of $\mathrm{Rh}$ nanoparticles that are noticeably larger in the case of catalyst NFLOx-Rh. As previously mentioned, Rh particles were not observed by TEM in the fresh catalysts. The average size is $2-5 \mathrm{~nm}$, (maximum size $8 \mathrm{~nm}$ ) in both carbon xerogels based catalysts, and $7 \mathrm{~nm}$ (maximum size $20 \mathrm{~nm}$ ) in catalyst NFLOx-Rh. a)

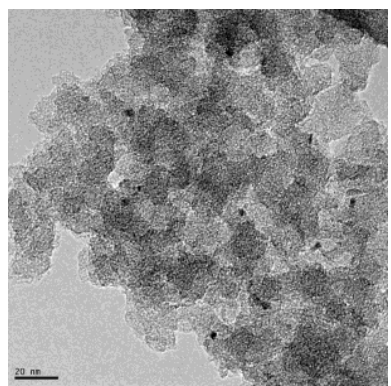

b)

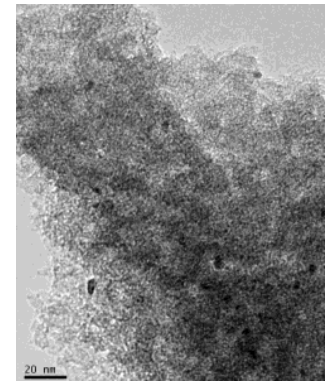

c)

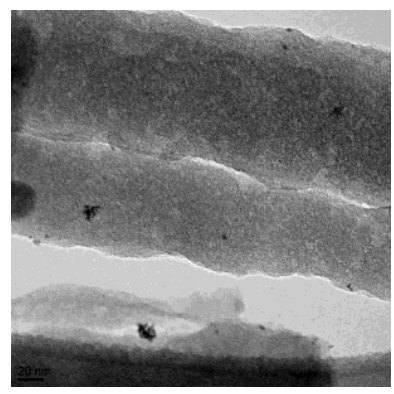

Figure 10. TEM images of used catalysts: (a) CX1Ox-Rh; (b) CX2Ox-Rh and (c) NFLOx-Rh.

Catalysts CX1Ox-Rh and CX2Ox-Rh were also analyzed by XPS. This technique reveals the presence of both $\mathrm{Rh}^{\prime}(309.6 \mathrm{eV})$ and $\mathrm{Rh}^{0}(307.5 \mathrm{eV})$. The proportion $\mathrm{Rh}^{0}$ was about $50 \%$ in both carbon xerogel based catalysts. The binding energy of N1s shows that nitrogen is found as amine.

Thus, the reduction of the $\mathrm{Rh}$ complex and the development of metallic particles could be behind the behaviour of the hybrid catalysts in the second catalytic run. However, it is striking that the effect is the opposite in catalysts prepared with carbon xerogels and with carbon nanofibres.

The enhanced activity of the carbon xerogel based catalysts after the first catalytic run could be explained by the presence of very small metallic particles. In order to clarify this point, a sample of catalyst CX1Ox-Rh was expressly reduced previous to the catalytic test. The reduction was carried out by treating the sample in $\mathrm{H}_{2}$ atmosphere ( $\left.\mathrm{p}=10 \mathrm{bar}\right)$, at $383 \mathrm{~K}$, during $4 \mathrm{~h}$. The reduced sample was also analyzed by TEM: well dispersed, small, metallic particles (1-4 nm) were observed. The reduced sample was tested in the hydrogenation of cyclohexene and the monitored hydrogen indicates that it is active as the original sample in the second run (Supporting information S3).

This result indicates that the high activity of catalysts $\mathrm{CX} 1 \mathrm{Ox}$ $\mathrm{Rh}$ and $\mathrm{CX} 2 \mathrm{Ox}-\mathrm{Rh}$ in the second run must be explained by the formation, during the reaction, of small metallic particles.

The catalytic activity decrease of catalyst NFLOx-Rh upon recycling can be explained considering that the sintering of metallic particles is important in this sample, and thus the increase of the particle size is responsible of the activity decrease. Additionally, the high activity of this catalyst in the first run could be a consequence of the formation of small $\mathrm{Rh}$ particles as soon as the reaction begins.

These results reveal that the support nature plays an important role in the catalysts properties. In particular, it seems that the surface of the carbon xerogels contributes to the stabilization of the small metallic particles while on the carbon nanofibres an important sintering process takes place.

The nature of the support seems also be responsible of the modification suffered by the anchored Rh complex in these hybrid catalysts. Results of previous works dealing with the heterogenization of the same diamine complex in several carbon materials did not show the reduction of the complex to $\mathrm{Rh}^{0}{ }^{[9]}$. Thus, the nature of the carbon material used as support plays a role not only in the accommodation of the metal complex (by means of surface chemistry and porosity) but also in promoting or hindering its reduction.

\section{Carvone hydrogenation}

Scheme 3 shows the basic reaction steps sequence of carvone hydrogenation, showing that three products can be obtained: the unsaturated ketone (carvotanacetone, CT), the saturated ketone (carvomenthone, $\mathrm{CM}$ ) and the hemicetal $(\mathrm{Hc})$ through the reaction with the solvent.

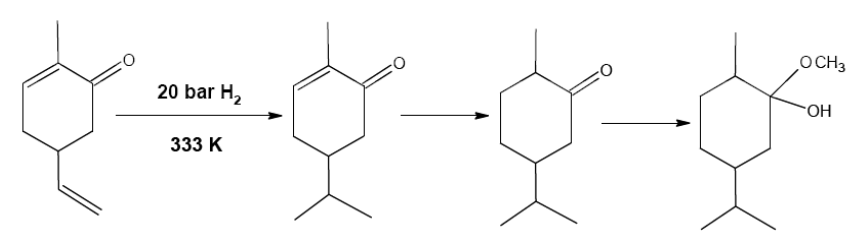

Carvone (Cv) Carvotanacetone (CT) Carvomenthone (CM) Hemicetal (Hc)

Scheme 3. Steps of the carvone hydrogenation reaction.

The results obtained with the homogeneous and the hybrid catalysts show that this reaction is slower than cyclohexene hydrogenation and the difference between the behaviour of the hybrid catalysts and the homogeneous complex is more pronounced. Figure 11 shows the hydrogen consumption measured with catalyst $\mathrm{CX} 1 \mathrm{Ox}-\mathrm{Rh}$ and the homogeneous complex $\mathrm{Rh}(\mathrm{NN}) \mathrm{Si}$. In this reaction hydrogen is consumed in different consecutive steps and thus $100 \%$ carvone conversion is not identified in the curve by a plateau. 


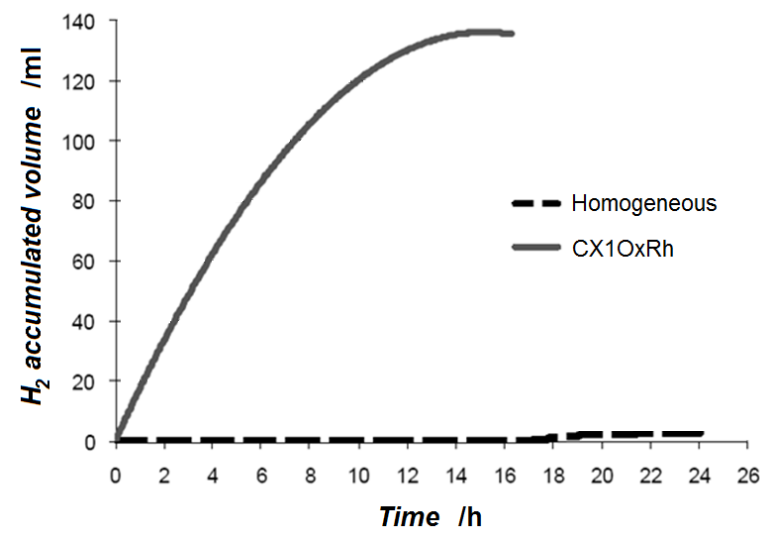

Figure 11. $\mathrm{H}_{2}$ uptake curves obtained during carvone hydrogenation with the $\mathrm{Rh}(\mathrm{NN}) \mathrm{Si}$ complex and catalyst CX1Ox-Rh. 5 vol. \% carvone in methanol, 20 bar $\mathrm{H}_{2}, 333 \mathrm{~K}$

To analyze the evolution of the reaction with time, several experiments were carried out stopping the process at different reaction time. Figure 12 shows the concentration of substrate and products (as mol \%) in the reaction medium as a function of time in the first $7 \mathrm{~h}$.

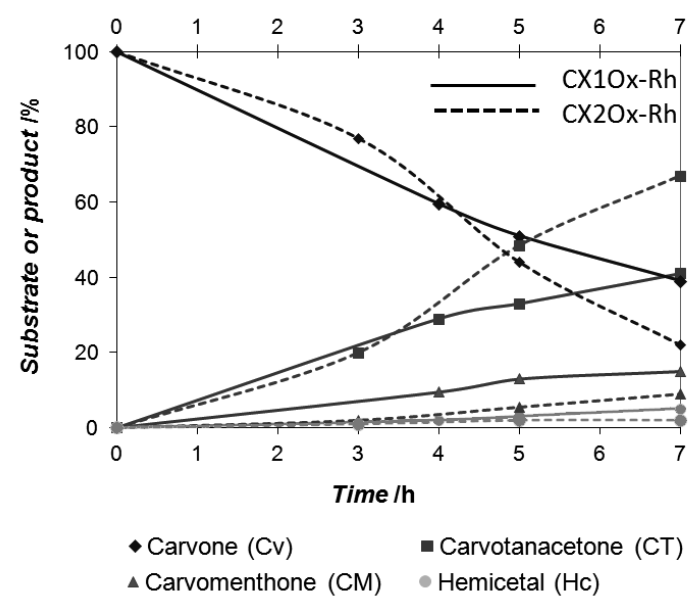

Figure 12. Catalytic activity and selectivity of $\mathrm{CX} 1 \mathrm{Ox}-\mathrm{Rh}$ and $\mathrm{CX} 2 \mathrm{Ox}-\mathrm{Rh}$ catalysts in carvone hydrogenation. 5 vol. \% carvone in methanol, 20 bar $\mathrm{H}_{2}$ 333K.

Data of Figure 12 show that after $7 \mathrm{~h}$, catalyst CX2Ox-Rh gives higher carvone conversion and selectivity to carvotanacetone than catalyst CX1Ox-Rh. In the case of catalyst CX1Ox-Rh, the final reaction time was $16 \mathrm{~h}$.

At this time, total carvone conversion was reached and the selectivity to carvomenthone was higher $(\mathrm{CM}=50 \%, \mathrm{CT}=35 \%)$.

Table 6 presents the product distribution obtained with the two hybrid catalysts at a $30 \%$ carvone conversion and at $7 \mathrm{~h}$ reaction time.

Taking into account that carvone is more voluminous than cyclohexene, diffusion limitations maybe more important and thus, the higher activity of catalyst $\mathrm{CX} 2 \mathrm{Ox}-\mathrm{Rh}$ can be related to the more external location of the Rh complex in this support ( $F=35$ in CX2Ox-Rh in front of $\mathrm{F}=16$ in catalyst $\mathrm{CX} 1 \mathrm{Ox}-\mathrm{Rh}$ ).

Regarding selectivity, data of Table 6 show differences between catalysts $\mathrm{CX} 1 \mathrm{Ox}-\mathrm{Rh}$ and $\mathrm{CX} 2 \mathrm{Ox}-\mathrm{Rh}$, however they are less pronounced than those found previously with catalysts prepared with carbon nanotubes and carbon nanofibres, where an important effect of the inner diameter of the tubular carbon supports was observed. ${ }^{[9,12]}$

\begin{tabular}{|c|c|c|c|c|c|c|}
\hline \multirow{4}{*}{ Sample } & \multicolumn{6}{|c|}{ Product distribution [\%] } \\
\hline & \multicolumn{3}{|c|}{ At $30 \%$ carvone conversion } & \multicolumn{3}{|c|}{ At $7 \mathrm{~h}$} \\
\hline & \multicolumn{6}{|c|}{ Run 1} \\
\hline & CT & CM & $\mathrm{HC}$ & CT & CM & $\mathrm{HC}$ \\
\hline CX10x-Rh & 75 & 23 & 2 & 67 & 29 & 4 \\
\hline \multirow[t]{2}{*}{ CX2Ox-Rh } & 89 & 8 & 3 & 86 & 11 & 3 \\
\hline & \multicolumn{6}{|c|}{ Run 2} \\
\hline CX10x-Rh & 68 & 24 & 8 & 21 & 63 & 16 \\
\hline CX2Ox-Rh & 84 & 15 & 1 & 73 & 20 & 7 \\
\hline
\end{tabular}

As observed in the hydrogenation of cyclohexene, the hybrid catalysts are more active in the second and successive runs of carvone hydrogenation. Figure 13 presents the product distribution as a function of time obtained with both catalysts in the second run. The data at $30 \%$ carvone conversion and at $7 \mathrm{~h}$ are presented in Table 6 . The selectivity pattern of catalyst CX1Ox-Rh reveals that it becomes very active to hydrogenate carvotanacetone $(\mathrm{CT})$ to carvomenthone $(\mathrm{CM})$. At $7 \mathrm{~h}$ the differences in selectivity between the two hybrid catalysts are very prominent.

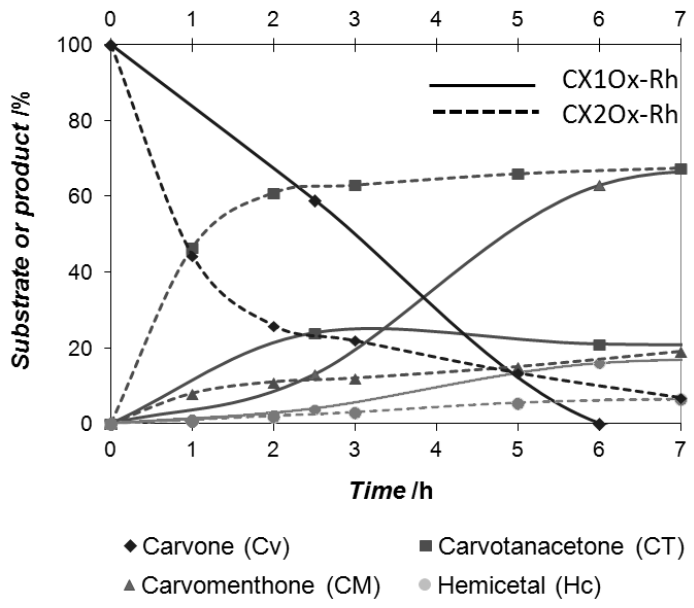

Figure 13. Catalytic activity and selectivity in the second run. Carvone hydrogenation. 5 vol. \% carvone in methanol, 20 bar $\mathrm{H}_{2}, 333 \mathrm{~K}$.

The TEM characterization of both used hybrid catalysts shows small and well dispersed metallic particles.

A sample of catalyst $\mathrm{CX} 1 \mathrm{Ox}-\mathrm{Rh}$ was also expressly reduced to determine the role of metallic $\mathrm{Rh}$ in the catalytic activity of the samples. The reduced catalyst was very active, $99 \%$ carvone conversion in 1 hour, but less selective: $\mathrm{CT}=38 \%, \mathrm{CM}=56 \%$, $\mathrm{Hc}=5 \%$.

It seems that the development of metallic $\mathrm{Rh}$ particles is behind the enhanced activity in the second run. However, there 
are differences in selectivity that must be due to some differences in the state or location of the active phase. This means that the Rh complex suffers important modifications during the hydrogenation reaction, but also that the resulting catalytic properties of the modified species are clearly influenced by the support characteristics.

The behaviour of the two hybrid catalysts investigated can be summarized as follows: i) Catalyst CX2Ox-Rh is more selective than $\mathrm{CX} 1 \mathrm{Ox}-\mathrm{Rh}$ to carvotanacetone, the first hydrogenation product of carvone meaning that in catalyst $\mathrm{CX} 2 \mathrm{Ox}-\mathrm{Rh}$ the hydrogenation of carvotanacetone is less favoured. ii) In the second run, both catalysts become more active and this can be attributed to the partial reduction of the Rh complex. iii) In the second run, catalyst CX1Ox-Rh becomes more selective to carvomenthone, indicating that the second hydrogenation step is enhanced.

According to these results, the following interpretation of the porosity effect can be suggested. In catalyst CX1Ox-Rh the active species is located in an inner position (as derived from the lower value of $F$ (see Table 3)) and thus it is more constrained. In such a situation, the first hydrogenation product (carvotancetone, CT) is very prone to interact again with the active site to be further hydrogenated, and this explains the selectivity of catalyst CX1OX$\mathrm{Rh}$ to carvomenthone. On the contrary, in a broader room (case of catalyst $\mathrm{CX} 2 \mathrm{Ox}-\mathrm{Rh}$ ), the probability for the first product to diffuse away from the active site is higher, preventing its further hydrogenation. This effect is even more pronounced in the second run, when part of the Rh complex is reduced.

\section{Conclusion}

Hybrid catalysts have been prepared by the covalent anchorage of the complex, $\left[\mathrm{Rh}(\mathrm{COD}) \mathrm{NH}_{2}\left(\mathrm{CH}_{2}\right)_{2} \mathrm{NH}\left(\mathrm{CH}_{2}\right)_{3} \mathrm{Si}\left(\mathrm{OCH}_{3}\right)_{3}\right] \mathrm{BF}_{4}$ on two carbon xerogels and on carbon nanofibers.

The active molecule is mainly located in supermicropores and produces a blockage of microporosity as deduced from the dimensions of the metal complex and gas adsorption data.

The hybrid catalysts are more active than the homogeneous complex for the cyclohexene and carvone hydrogenations. However, they suffer important modifications under reaction conditions, in particular a partial reduction of the Rh complex to $\mathrm{Rh}^{0}$. This phenomenon must be related to the nature of the support as it was not previously observed with other carbon materials.

The inner location of the active species or the complex reduction producing $\mathrm{Rh}$ particles during reaction make catalyst NFLOx-Rh the most active in the hydrogenation of cyclohexene, in a first run. However, the sintering of the $\mathrm{Rh}$ particles deactivates this catalyst in consecutive runs. The formation of small and stable $\mathrm{Rh}$ particles in the two carbon xerogel based catalysts (CX1Ox-Rh and CX2Ox-Rh) produces an enhancement of the activity after the first catalytic run for the two hydrogenation reactions. No effect of mesopore size and volume is observed in the hydrogenation of cyclohexene. Contrarily, clear differences in selectivity were observed in carvone hydrogenation. These differences must be due to the inner location of the active species in support CX1Ox and the effect of this constrained environment to promote the successive hydrogenation steps.

The nature and properties of the carbon material used as support have an important effect on the modification suffered by the anchored Rh complex under reaction conditions resulting in changes in the activity and selectivity of the resulting system.

\section{Experimental Section}

\section{Supports}

Two carbon xerogels (CX1 and CX2) have been used as supports. They have been prepared at the Department of Chemical Engineering of the Liège University (Belgium) following the method described in the literature. ${ }^{[21]}$ The samples were grinded and sieved in order to have a particle size between 1.0 and $1.4 \mathrm{~mm}$.

Carbon nanofibers (NFL), provided by professor A. Oya from the Graduate School of Engineering of the Gunma University (Japan), were also used as support. These nanofibers are prepared from lignin. The samples were submitted to a heat treatment in synthetic air flow (40 ml $\mathrm{min}^{-1}, 623 \mathrm{~K}, 3 \mathrm{~h}$ ) to develop phenol type groups. ${ }^{[22]}$ The oxidized carbon materials are named CX1Ox, CX2Ox and NFLOx.

\section{Rh complex}

The synthesis of the diamine rhodium complex $\left[\mathrm{Rh}(\mathrm{COD}) \mathrm{NH}_{2}\left(\mathrm{CH}_{2}\right)_{2} \mathrm{NH}\left(\mathrm{CH}_{2}\right)_{3} \mathrm{Si}\left(\mathrm{OCH}_{3}\right)_{3}\right] \mathrm{BF}_{4}$ (named $\mathrm{Rh}(\mathrm{NN}) \mathrm{Si}$ ) was carried out using standard Schlenk techniques, and following the reported procedure. ${ }^{[9]}$

\section{Preparation of catalysts}

The hybrid catalysts were prepared by impregnation of the oxidized supports $(200 \mathrm{mg})$ with a methanol solution $(60 \mathrm{ml})$ of the $\mathrm{Rh}(\mathrm{NN}) \mathrm{Si}$ complex (20 mg, $0.038 \mathrm{mmol})$. The used amounts of support and complex correspond to a $2 \mathrm{wt} \% \mathrm{Rh}\left(192 \mu \mathrm{mol} \mathrm{g}^{-1}\right)$. The mixture was maintained under reflux for $21 \mathrm{~h}$ and then, the catalyst was recovered by filtration and washed with methanol in Soxhlet for $24 \mathrm{~h}$. Analysis of the washing solution showed that the removed complex corresponds to about 0.1 wt $\% \operatorname{Rh}\left(9 \mu \mathrm{mol} \mathrm{g}^{-1}\right)$. Afterwards, the catalysts were vacuum dried for $24 \mathrm{~h}, \mathrm{RT}$. The three prepared catalysts are named CX1Ox-Rh, CX2Ox-Rh and NFLOx-Rh.

\section{Characterization of supports and catalysts}

The original and oxidized supports were characterized using the following techniques.

Gas adsorption (of $\mathrm{N}_{2}$ at $77 \mathrm{~K}$ and $\mathrm{CO}_{2}$ at $273 \mathrm{~K}$ ), using the automatic volumetric apparatus Autosorb-6B. The samples were previously degassed at $523 \mathrm{~K}$ for $4 \mathrm{~h}$. The textural properties of the samples (BET surface area, pore volumes of different size range, pore size distributions) have been determined as described in the literature. ${ }^{[15]}$

Transmission and Scanning Electron Microscopy were used, with a TEM equipment JEOL JEM-2010 microscope and a SEM equipment HITACHI S-3000N).

The study of the surface chemistry has been carried out by Temperature Programmed Desorption (TPD), using a thermobalance SDT TA Instruments 2960 coupled to a mass spectrometer Blazers MSC 200 Thermostar. Approximately $10 \mathrm{mg}$ of the sample were heated at $20 \mathrm{~K} \mathrm{~min}^{-1}$ up to $1300 \mathrm{~K}$ in $20 \mathrm{ml} \mathrm{min}^{-1} \mathrm{He}$ flow.

The hybrid catalysts were characterized by ICP-OES to determine the rhodium content in the catalysts, using the methodology described in the literature. ${ }^{[9]}$ XPS analysis was used employing a VG-Microtech Multilab 3000 spectrometer. For the gas adsorption $\left(\mathrm{N}_{2}\right.$ and $\left.\mathrm{CO}_{2}\right)$ the samples were outgassed at $333 \mathrm{~K}$ for $12 \mathrm{~h}$ (the temperature was low to avoid the complex degradation). The textural properties of the supports were also measured after outgassing under these conditions and results were similar to those obtained with the standard conditions. TEM observation of fresh and used catalysts was also realized.

\section{Catalytic activity and recycling}

The catalytic properties of the hybrid catalysts were tested in the hydrogenation of cyclohexene and carvone. Reactions were carried out in a stainless steel Parr reactor $(40 \mathrm{ml})$ magnetically stirred (1100 $\mathrm{rpm})$. The reaction vessel is equipped with a gas inlet valve for 
charging and purging the gas into the reactor and a pressure gage for the pressure control. The reactor is placed inside a heated bath with a recirculation water pump and a thermocouple. The experimental setup contains, as well, a device to monitor the hydrogen consumption during reaction.

For cyclohexene hydrogenation, $30 \mathrm{mg}$ of the hybrid catalyst were introduced in the reactor, along with $10 \mathrm{ml}$ of a $5 \mathrm{vol}$. \% solution of cyclohexene in methanol. The reactor was pressurized with $\mathrm{He}$ and purged three times, then $\mathrm{H}_{2}$ was filled in and evacuated three times, and finally the $\mathrm{H}_{2}$ pressure was set at 10 bar. Then, the reactor was placed in the thermostatic bath at the selected temperature of $333 \mathrm{~K}$. The homogeneous process was carried out using $1.5 \mathrm{mg}(3 \mu \mathrm{mol})$ of the $\mathrm{Rh}(\mathrm{NN}) \mathrm{Si}$ complex and keeping all the conditions as indicated above.

Carvone hydrogenation tests were carried out using the same methodology and temperature but with 20 bar $\mathrm{H}_{2}$ pressure.

Reactants and products were analyzed by gas chromatography using the HP 6890 equipment with a FID detector and a HP-1 Methyl Siloxane column ( $30 \mathrm{~m} \times 250 \mu \mathrm{m} \times 0.25 \mu \mathrm{m})$.

Recycling tests were carried out as follows: after a catalytic run, the catalyst was separated from the reaction media by filtration in air and then it was washed with fresh solvent. Afterwards it was used in a new catalytic run under the same conditions.

\section{Acknowledgements}

The authors thank the financial support to MICINN, Project MAT2009-07150, to GVA and FEDER, Project Prometeo 2009/047, and to MEC for the FPU scholarship of C.C.Gheorghiu.

Keywords: rhodium complex $\bullet$ hybrid catalysts $\bullet$ carbon xerogels $\bullet$ carbon nanofiber $\cdot$ hydrogenation

[1] B. Pugin, Journal of Molecular Catalysis A: Chemical 1996, 107, 273-279.

[2] F. Goettmann, C. Sanchez, Journal of Materials Chemistry 2007, 17, 2430.

[3] E. E. Santiso, M. K. Kostov, A. M. George, M. B. Nardelli, K. E. Gubbins, Applied Surface Science 2007, 253, 5570-5579.

[4] E. Auer, A. Freund, J. Pietsch, T. Tacke, Applied Catalysis A: General 1998, 173, 259-271

[5] C. Freire, A. R. Silva, Carbon Materials for Catalysis (Eds: P. Serp, J. L. Figueiredo), John Wiley \& Sons 2008, 267-307.
[6] D. S. Su, ChemSusChem 2011, 4, 811-813

[7] P. Serp, E. Castillejos, ChemCatChem 2010, 2, 41-47

[8] J. A. Díaz-Auñón, M. C. Román-Martínez, C. Salinas-Martínez De Lecea P. C. L'Argentière, E. A. Cagnola, D. A. Liprandi, M. E. Quiroga, Journal of Molecular Catalysis A: Chemical 2000, 153, 243-256.

[9] L. J. Lemus-Yegres, M. C. Román-Martínez, I. Such-Basáñez, C. Salinas-Martínez De Lecea, Microporous and Mesoporous Materials 2008, 109, 305-316.

[10] L. Lemus-Yegres, I. Such-Basáñez, C. Salinas-Martínez De Lecea, P. Serp, M. C. Román-Martínez, Carbon 2006, 44, 605-608.

[11] L. J. Lemus-Yegres, I. Such-Basáñez, M. C. Román-Martínez, C. Salinas-Martínez De Lecea, Applied Catalysis A: General 2007, 331, 2633.

[12] L. J. Lemus-Yegres, M. Pérez-Cadenas, M. C. Román-Martínez, C. Salinas-Martínez De Lecea, Microporous and Mesoporous Materials 2011, 139, 164-172.

[13] K. S. W. Sing, D. H. Everett, R. A. W. Haul, L. Moscou, R. A. Pierotti, J. Rouquerol, T. Siemieniewska, Pure and Applied Chemistry 1985, 57, 603-619.

[14] E. P. Barrett, L. G. Joyner, P. P. Halenda, Journal of the American Chemical Society 1951, 73, 373-380.

[15] F. Rodríguez-Reinoso, A. Linares-Solano, Chemistry and Physics of Carbon, 1988, 21.

[16] F. Rouquerol, J. Rouquerol, K. Sing, Adsorption by powders \& porous solids - Principles, Methodology and Applications, Academic Press, London 1999.

[17] J. L. Figueiredo, M. F. R. Pereira, M. M. A. Freitas, J. J. M. Órfão, Carbon 1999, 37, 1379-1389.

[18] G. S. Szymanski, Z. Karpinski, S. Biniak, A. Swiatkowski, Carbon 2002, 40, 2627-2639.

[19] http://www.lasurface.com/accueil/index.php.

[20] S. Pariente, P. Trens, F. Fajula, F. Di Renzo, N. Tanchoux, Applied Catalysis A: General 2006, 307, 51-57.

[21] N. Job, A. Théry, R. Pirard, J. Marien, L. Kocon, J. N. Rouzaud, F. Béguin, J. P. Pirard, Carbon 2005, 43, 2481-2494.

[22] P. V. Samant, Filomena Gonçalves, M. M. Freitas, M. F. Pereira, J. L. Figueiredo, Carbon 2004, 42, 1321-1325.

Received: ((will be filled in by the editorial staff))

Published online: ((will be filled in by the editorial staff) 
Entry for the Table of Contents (Please choose one layout only)

Layout 1:

\section{FULL PAPER}

A nosy partner. Partial complex reduction during hydrogenation reactions has been observed in carbon xerogels supports leading to a catalytic activity enhancement. Selectivity to intermediate product could be modulated by the mesopore size of the support.

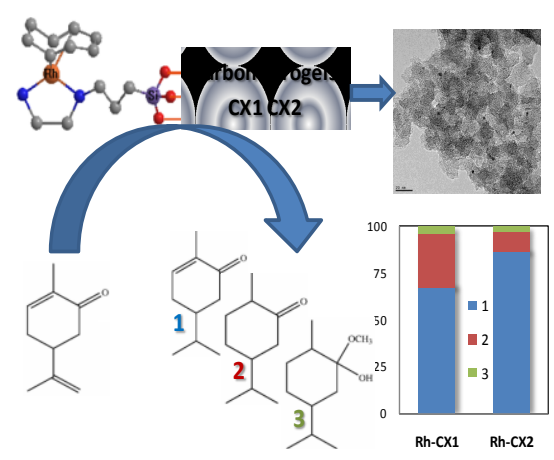

C. C. Gheorghiu, C. Salinas Martínez de Lecea, M.C. Román Martínez *

Page No. - Page No.

Support effects in a $\mathrm{Rh}$ diamine complex heterogenized on carbon materials.

Layout 2:

\section{FULL PAPER}

((The TOC Graphic should not exceed the size of this area))
Text for Table of Contents----continued.
Author(s), Corresponding Author(s)*

Page No. - Page No.

Title 


\section{Support effect in a Rh diamine complex heterogenized on carbon materials}

C. C. Gheorghiu, C. Salinas Martínez de Lecea, M.C. Román Martínez

\section{Supporting information}

a)

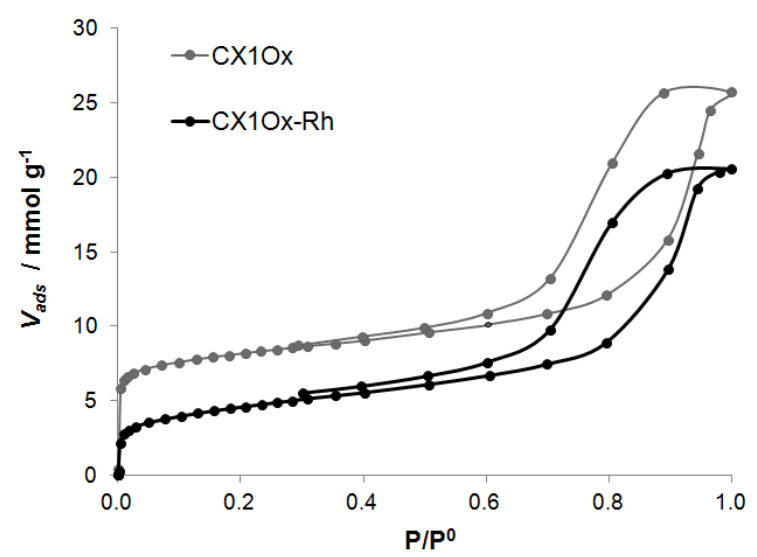

c)

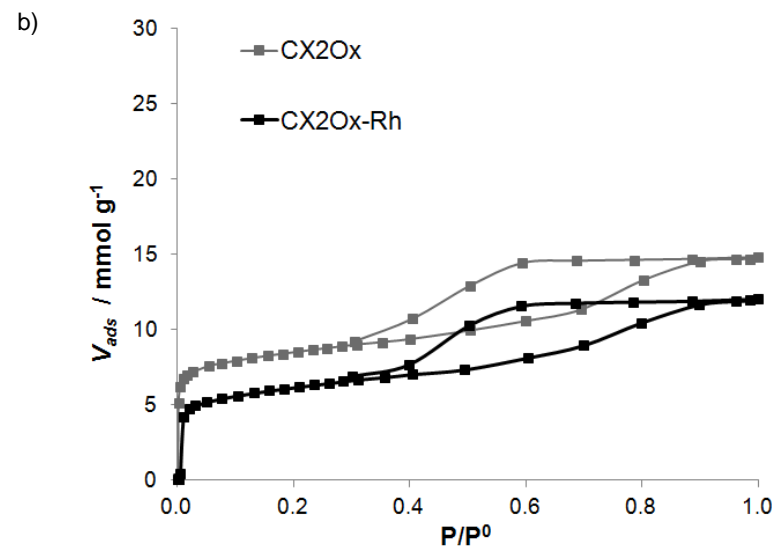

Figure $\mathrm{S} 1 . \mathrm{N}_{2}$ adsorption isotherms for (a) CX1Ox and CX1Ox-Rh(NN)Si; (b) CX2Ox and CX2Ox-Rh(NN)Si; (c) NFLOx and NFLOx-Rh(NN)Si.

a)

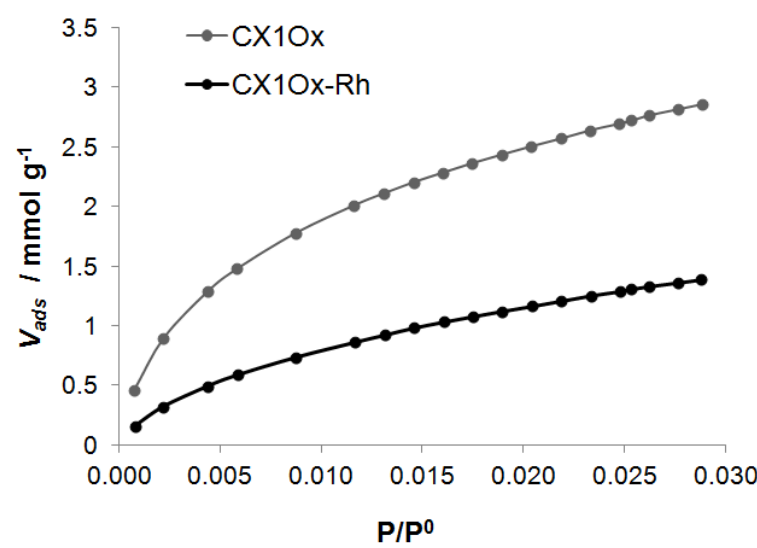

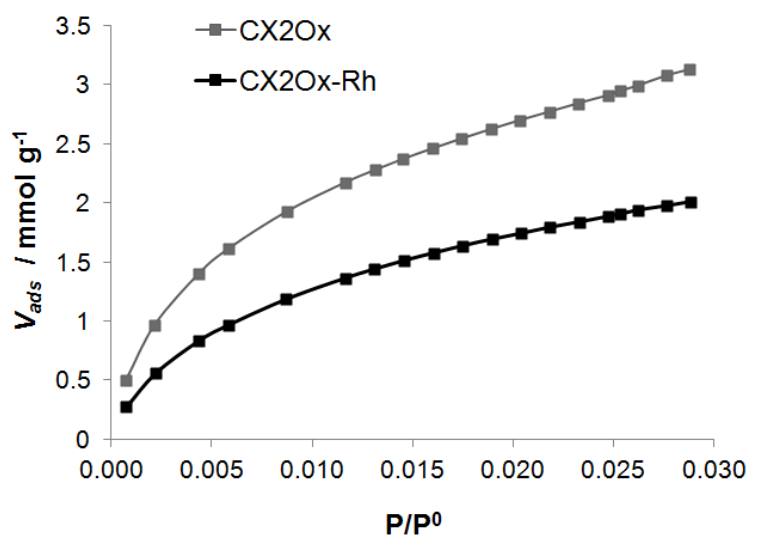


c)

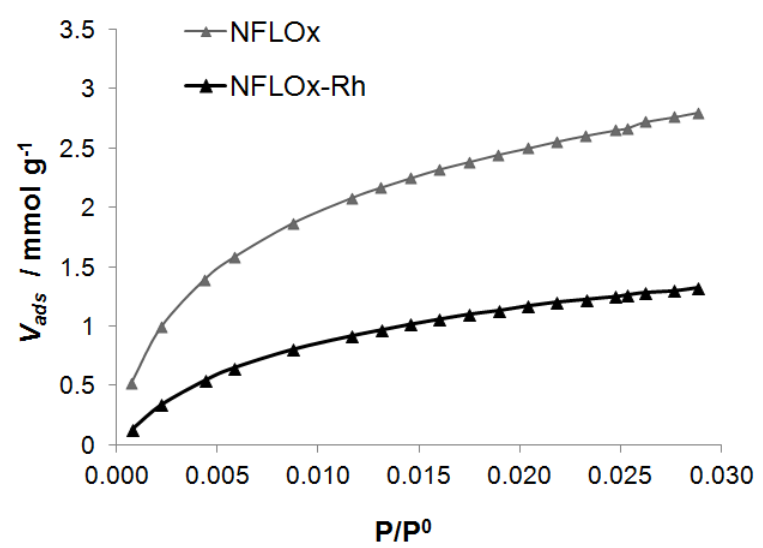

Figure S2. $\mathrm{CO}_{2}$ adsorption isotherms for (a) CX1Ox and CX1Ox-Rh; (b) CX2Ox and CX2Ox-Rh; (c) NFLOx and NFLOx-Rh.

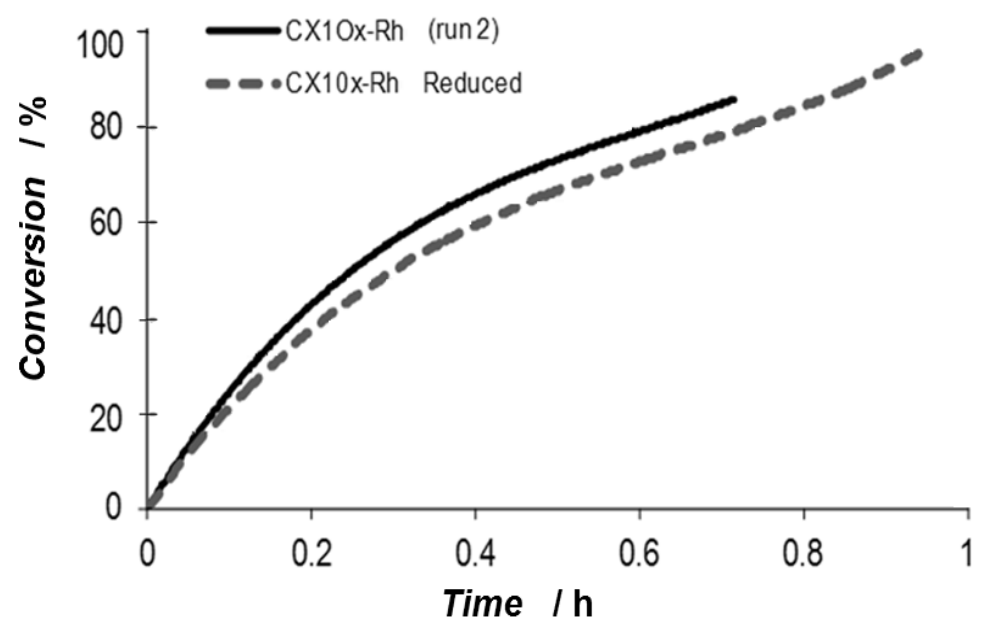

Figure S3. Hydrogen uptake curves for CX1Ox-Rh (run 2) and reduced CX1Ox-Rh 